\title{
Femoral mechanical performance of precocial and altricial birds: a simulation study
}

\author{
Xinsen Wei and Zihui Zhang ${ }^{*}$ (i)
}

\begin{abstract}
Background: As the major load-bearing structures, bones exhibit various properties related to mechanical performance to adapt to different locomotor intensities. The habits and ontogenetic changes of locomotion in animals can, thus, be explored by assessing skeletal mechanical performance.

Methods: In this study, we investigated the growing femoral mechanical performance in an ontogenetic series of Cabot's Tragopans (Tragopan caboti) and Pigeons (Columba livia domestica). Micro-computed tomography-based finite element analysis was conducted to evaluate the stress, strain, and strain energy density (SED) of femora under axial and radial loading.

Results: Femora deflected medio-laterally and dorso-ventrally under axial and radial loading, respectively. Femora deformed and tensed more severely under radial loading than axial loading. In adult individuals, Cabot's Tragopans had lower strain and SED than pigeons. During ontogeny, the strain and SED of pigeons decreased sharply, while Cabot's Tragopans showed moderately change. The structural properties of hatchling pigeons are more robust than those of hatchling Cabot's Tragopans.

Conclusions: Limb postures have dominant effect on skeletal deformation. The erect posture is preferred by large mammals and birds to achieve a high safety factor of bones during locomotion. Adult Cabot's Tragopans have stronger femora than pigeons, reflecting a better bone adaption to the terrestrial locomotion of the studied pheasant species. Changes in strain and SED during growth reflect the marked difference in locomotor ability between precocial and altricial hatchlings. The femora of hatchling Cabot's Tragopans were built with better energy efficiency than deformation resistance, enabling optimized mechanical performance. In contrast, although weak in mechanical function at the time of hatching, pigeon femora were suggested to be established with a more mature structural design as a prerequisite for rapid growth. These results will be helpful for studies regarding developmental patterns of fossil avian species.
\end{abstract}

Keywords: Biomechanics, Cabot's Tragopan, Femur, Finite element analysis, Pigeon

\section{Background}

Hatchling birds are known for their diverse levels of maturity. While precocial species hatch with well-developed eyes, feathery down and strong limbs, altricial

*Correspondence: zihuizhang@cnu.edu.cn

College of Life Sciences, Capital Normal University, Beijing 100048, China species are still embryo-like upon hatching. Altricial hatchlings are so helpless that they cannot survive without parental care (Ricklefs 1979a). The musculoskeletal system shows remarkable diverse extents of development among different hatchlings (Ricklefs 1979a, b).

The mechanical performance of the major loadbearing structures, the long bones, significantly affects animal locomotion (Currey 2003; Ruff et al. 2006). It is 
common to find a correlation between the mechanical performance of bone and the locomotor ability of animals. Carrier and Leon (1990) found that the breaking load of hind limb bones of California Gulls (Larus californicus) decreased relative to the body mass with growth. California Gulls are semi-precocial species; the robust bones of hatchling gulls allow them to walk soon after hatching. The discrepancy in the locomotor ability between precocial and altricial hatchlings is also reflected in the mechanical performance of their bones. Wei and Zhang (2019) observed that the breaking load of femora of hatchling Quails (Coturnix coturnix japonica) was significantly higher than that of hatchling Pigeons (Columba livia domestica), suggesting that the bones of precocial chicks are stronger. Moreover, the femoral breaking load of quails showed negative allometry during ontogeny, while the femoral breaking load of pigeons showed positive allometry. The different allometric trends of the femoral breaking load of quails and pigeons correspond to the decreasing and increasing locomotor intensity during the development of the two birds, respectively, which reflects the remarkably different ontogenetic changes in the locomotor ability of precocial and altricial birds.

Currey (2003) suggested that at least three properties should be considered when evaluating the mechanical performance of long bones: their strength, stiffness, and mass. Bone strength, which reflects the resistance of bones to fracture, has attracted the most research attention. However, bone stiffness and mass are just as important as strength in making a bone optimal for locomotion. Considerable energy is spent on driving limbs during locomotion. As such, limbs with lighter bones achieve better energy efficiency than limbs with heavier bones. Furthermore, bone stiffness estimates a bone's resistance to deformation. Bones with low stiffness can fail through excessive deformation, even if no fracture has occurred (Dumont et al. 2009). Additionally, bone stiffness affects the total weight of a limb. Alexander et al. (1990) suggested that the deflection of a bone must be counteracted by the contraction of muscles. Flexible bones require muscles to contract further distances to counteract the additional bone deflection, and longer fibers are needed to allow the additional shortening of muscles. However, because the cross-sectional area of muscle is fixed to achieve a required force, any increase in length will lead to an increase in muscle mass and, thus, increase limb weight. As such, an optimal level of bone stiffness is needed to minimize the total mass of a limb. In conclusion, bones should be evaluated as multifunctional objects; their mechanical performance not only affects their resistance to load but also the operation of the locomotor system.
The mechanical performance of bones can be quantitatively evaluated using engineering parameters. Dumont et al. (2009) suggested that stress and strain energy can be used to evaluate the strength and energy efficiency of bones, respectively. Stress constitutes force per unit area. As a material will be damaged by a certain stress level, higher stress levels cause lower material strength. Strain energy is the energy stored inside a structure when it is deformed under a force. The more energy that is consumed by bone deformation, the less energy is used for locomotion. Therefore, a bone with lower strain energy will achieve higher energy efficiency. As strain energy exhibits a positive correlation with bone volume, the strain energy per unit volume (strain energy density (SED)) is usually adopted in comparative studies (Dumont et al. 2009). Furthermore, the strain is a measurement of the extent of deformation and can, thus, be used to evaluate the deformation resistance of bones (Currey 1999). Because of the regular shapes of engineering components, measurements such as stress and strain can be calculated using formulas of mechanics. In contrast, bones are not only geometrically irregular but also exhibit extremely complex material properties. Thus, engineering formulas can only be adopted for approximate calculations in bone studies, whereas they are not precise enough when absolute parameter values are required. Finite element analysis is a powerful tool to solve this problem. By discretely dividing a complex structure into a collection of elements with simple geometry, the finite element method effectively simplifies the mechanical analysis of complex objects such as bone (Rayfield 2007, 2019). Additionally, as the finite element model is used as the experimental object, parameters such as material properties, geometry, and load are easily controlled and modulated. As such, the study is highly controlled, and such operations are hardly achieved in actual experiments (Morgan and Bouxsein 2005; Rayfield 2007).

Wei and Zhang (2019) have compared the femoral mechanical performance of precocial and altricial birds by analyzing the breaking load, cross-sectional geometry, and elastic modulus of femora. However, a comprehensive analysis of bones from a multifunctional perspective is still lacking. Therefore, in the present study, we adopted the finite element method to analyze the ontogenetic changes of long bone mechanical performance in the Cabot's Tragopan (Tragopan caboti) and domestic Pigeon (Columba livia domestica) by analyzing stress, strain, and SED of femora. Based on our data, attempts were made to clarify the divergence in the ontogenetic strategy between altricial and precocial birds. 


\section{Methods}

\section{Animals and femoral samples}

This study included 9 Cabot's Tragopans and 30 pigeons. The Cabot's Tragopan is a ground-dwelling species, nests in trees; newly hatched chicks are precocial, possessing the ability to move, and will leave the nest 3 days after hatching to forage with their parents (Wang et al. 2021). The domestic pigeon, in contrast, is a typical altricial bird. Pigeon chicks are unable to move until 5 days of age (Olea et al. 2016), and after which point they use their legs to compete with siblings and for other in-nest activities. They grow rapidly, and begin to stretch and exercise their wings at the age of about 3 weeks, one week before they leave the nest.

Pigeons (body mass: 60-560 g) were collected from a commercial farm in Beijing, China, and decapitated at the age of $4,7,14,21,28,56,112,168,252$, and 336 days. They were incubated naturally, birds younger than 30 days were fed by both parents, and birds older than 30 days were reared in nursery and flying loft with sufficient food and water reply. Body mass was measured with a digital balance ( $0.01 \mathrm{~g}$ precision) before decapitation and skeletal preparation. This research protocol was approved by the Animal Care and Ethics Committee of my university. Cabot's Tragopans (body mass: 23-1469 g) were collected from Tragopan Breeding Center of Beijing Normal University. As no age record was available for Cabot's Tragopans, they were grouped by body mass and feather characteristics (Wen and Zheng 1998): "hatchling" ( $n=1, \mathrm{H} 1)$, "juvenile" $(n=2, \mathrm{~J} 1-\mathrm{J} 2)$, "sub-adult" $(n=1, \mathrm{SA} 1)$, and "adult" $(n=5, \mathrm{~A} 1-\mathrm{A} 5)$. The entire right femur of each individual was dissected and then soaked in normal saline solution and frozen at $-20{ }^{\circ} \mathrm{C}$ to keep its physical properties constant (Pelker et al. 1984).

\section{Micro-computed tomography (CT) and cross-sectional bone properties}

Micro-CT images were collected for each femoral sample using a Skyscan 1172 micro-CT scanner (Nano Scientific Instruments Co., Ltd, Shanghai, China). According to the size of the femora, four scan resolutions were set: $7.96 \mu \mathrm{m}$ (source voltage: $49 \mathrm{kV}$, source current: 179 $\mu \mathrm{A}$, exposure: $900 \mathrm{~ms}$ ), $12.96 \mu \mathrm{m}$ (source voltage: $70 \mathrm{kV}$, source current: $141 \mu \mathrm{A}$, exposure: $1800 \mathrm{~ms}$ ), $17.41 \mu \mathrm{m}$ (source voltage: $65 \mathrm{kV}$, source current: $380 \mu \mathrm{A}$, exposure: $450 \mathrm{~ms}$ ), and $19.97 \mu \mathrm{m}$ (source voltage: $54 \mathrm{kV}$, source current: $185 \mu \mathrm{A}$, exposure: $320 \mathrm{~ms}$ ). Two hydroxyapatite samples of known density were scanned at each scan setting to convert Hounsfield units to density.

Cross-sectional images of femora were imported into IMAGEJ 1.51 as stacks, and the plug-in BoneJ was adopted to measure geometric parameters of cross-sections, which included the cross-sectional area $(A)$, diameter $(D)$, moment of inertia $(I)$, and polar moment of inertia $(J)$ (Doube et al. 2010). The average values of the images of the entire diaphysis and midshaft were calculated (Wei and Zhang 2019).

\section{Three-point bending tests}

To estimate the femoral elastic modulus, three-point bending tests were conducted for each femur using an Instorn 5985 material-testing machine (Beijing Institute of Technology, Beijing, China). The femora were loaded along the dorso-ventral direction at the mid-diaphysis to failure, with the loading points displacing at a rate of $3 \mathrm{~mm} / \mathrm{min}$ (Currey 1999; Jepsen et al. 2015). The reaction force and displacement were automatically recorded by the computer.

The femoral elastic modulus $(E)$ was calculated by the following formula (Jepsen et al. 2015):

$$
E=\frac{K l_{0}^{3}}{48 I_{\mathrm{ml}}}
$$

where $K$ is stiffness, $l_{0}$ is the span length, and $I_{\mathrm{ml}}$ is the moment of inertia around the medio-lateral axis at the load point. The load and displacement of the femur show a linear relationship at the initial stage of deformation, and stiffness is the ratio of load-displacement at the linear stage. Linear regression analysis was performed between load and displacement of the linear deformative stage; the resulting slopes represent femoral stiffness.

Hatchlings-to-adult ratios of bone length, diameter, cross-sectional area, polar moment of inertia, and elastic modulus where used to evaluate the precocity of structural and material properties of the newborn individuals were calculated.

\section{Finite element analysis}

Within each age group, one pigeon with a body mass close to the mean body mass was selected as a representative pigeon. Finite element analysis was performed on the ten selected pigeons and on all the Cabot's Tragopans. The cross-sectional images of the femora were converted into 3D models using MIMICS (v. 17) (Fig. 1a-c). Then the Geomagic Studio was adopted to reconstruct a NURBS (nonuniform rational B-splines) curve for each 3D model; the mini-defects of femoral models were corrected by this operation as to not interfere with the finite element analysis results. At last, the models were discretized with quadratic tetrahedral elements in ABAQUS (Simulia) (Fig. 1d). FEA simulations were fulfilled with the support from School of Biological Science and Medical Engineering, Beihang University. 


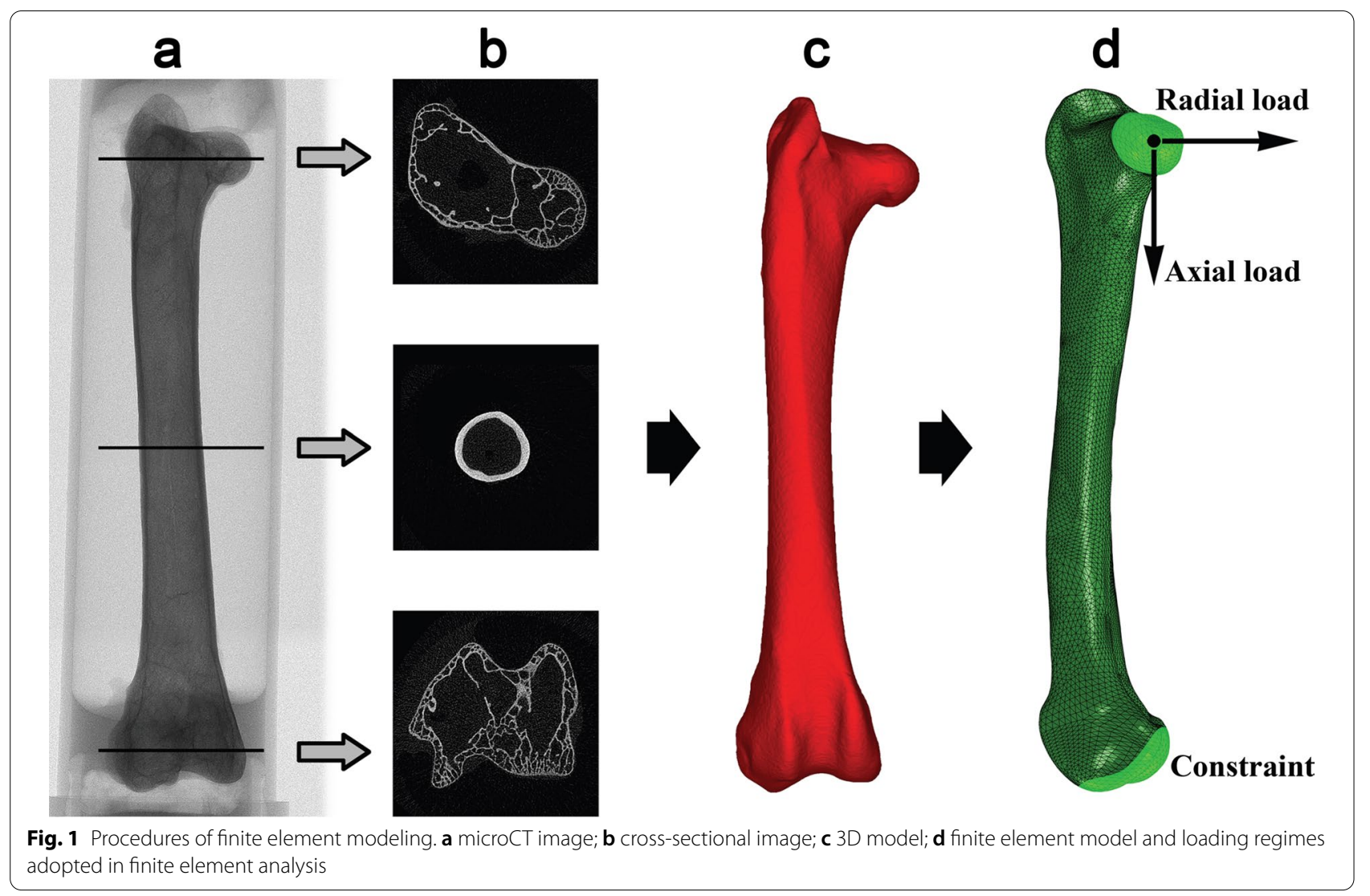

The isotropic but inhomogeneous elasticity properties were assigned to the elements of each model. Micro-CT Hounsfield unit (HU) values and bone density $(\rho)$ are linearly correlated, and the bone density is a power function to the elastic modulus (Helgason et al. 2008; Eberle et al. 2013). For pigeons and Cabot's Tragopans, the HU-density and density-elasticity relationships were calculated separately to obtain species-specific relationships for material assigning. Using the two hydroxyapatite samples of known density, the HU-density relationship was derived for each scan setting. Then the density of middiaphysis of femora was calculated based on the derived HU-density relationships. Femoral density and the elastic modulus calculated from the three-point bending test were imported into SPSS 22.0 one-to-one correspondence, and the power function curve fitting was performed to achieve density-modulus relationships. At last, each element was assigned an elastic modulus based on the local HU values following the species-specific relationships calculated above. The passion's ratio of 0.3 was assigned to all finite element models (Currey 2002; Bishop et al. 2018). The trabeculae were also taken into account in the femoral model. They were treated as a continuum, but the elements were assigned extremely low elastic modulus $(0.0001 \mathrm{MPa})$ to reflect interspace within the tissue (density lower than $0.01 \mathrm{~g} / \mathrm{cm}^{3}$ ) (Crawford et al. 2003).

For each mode, two different loading conditions were simulated independently: the axial load and the radial load (Fig. 1d). As the sagittal plane is the predominant plane of hind limb motion, the sagittal force is the predominant component of the hip reaction force (Clark and Alexander 1975; Alexander et al. 1979b; Goetz et al. 2008). The sagittal force at any angle can be decomposed into an axial and radial component. Thus, how femora bear axial and radial loading is vital for the terrestrial locomotion of birds.

The load was applied on a reference point, which was coupled with the surface of the femoral head to simulate the effect of the acetabulum on the femur head. The body weight was used as the magnitude of load for each simulation. The surface of the femoral distal epiphysis was constrained to represent the restraint of the knee joint to the femur (Fig. 1d).

For all simulations, the von Mises stress, maximum principal strain, minimum principal strain, and SED within the femoral models were calculated. Von Mises stress is the equivalent stress derived based on maximum distortion energy theory, with high accuracy in predicting fracture and yielding of isotropic material (Doblaré 
et al. 2004). For each simulation, the highest stress within the diaphysis of each model was recorded. The principal strains are the normal strains on the planes of zero shear stress. The greatest of the three principal strains of an element in a 3D coordinate system is called a maximum principal strain, and the most negative one is the minimum principal strain (Gere 2001). The tensile and compressive strains are customarily defined as positive and negative, respectively; therefore, the maximum and minimum principal strains reflect the degree of tensile and compressive deformation, respectively. The maximum and minimum principal strains at the proximal end, mid-diaphysis, and distal end were recorded, and then were averaged to represent the maximum and minimum principal strains of the bone.

\section{Results}

\section{Hounsfield unit value-density and density-modulus} relationships

Because different scan settings will lead to different Hounsfield unit value-density relationships, four $H U$ - $\rho$ relationships were established corresponding to four scan settings. Two species-specific density-modulus relationships were calculated for pigeons and Cabot's Tragopans (Table 1 ). According to the $\rho-E$ relationships and within the range of naturally occurring bone densities, $E$ will always be larger in Cabot's Tragopans. However, pigeons have a larger power of density than Cabot's Tragopans in the $\rho-E$ relationship, which gives them a sharper increase of $E$ with the increase of density.

\section{Deformation and strain}

Axial and radial loads bent femora along medio-lateral and dorso-ventral orientations, respectively (Fig. 2). In both pigeons and Cabot's Tragopans, the highest strain due to axial loading was located in both the proximal and distal ends of the femoral diaphysis. The highest strain due to radial loading was found at the distal diaphysis, and the strain gradually decreased from the distal end to the proximal end. However, the strain of the mid-diaphysis of 4- and 7-day-old pigeons was relatively higher than that of other individuals. During growth, the femoral strain of pigeons and Cabot's Tragopans both decreased but with different trends (Fig. 3). Pigeons showed a rapid decline in femoral strain during early growth, and this strain then plateaued from 28 days after hatching. The strain of young birds was up to tenfold higher than that of adults. In contrast, the femoral strain of Cabot's Tragopans decreased moderately during growth, and young birds had a similar strain as that of adults. The femoral strain of Cabot's Tragopans was lower than pigeons during all the developmental stages, and differences between young birds of the two species were greater than those between adults (Table 2).

\section{Stress}

Femoral stress increased with growth in both pigeons and Cabot's Tragopans (Fig. 3). The femoral stress of pigeons increased sharply during early growth and then plateaued from 21 days after hatching; however, 28-dayold pigeons exhibited significantly lower stress than the pigeons of other age groups. Cabot's Tragopans showed a moderate increase in femoral stress during growth. In pigeons, femoral stress of adults was 4.52-fold and 3.35fold higher than that of young birds under axial and radial loading, respectively. These values were 2.29 -fold and 2.27-fold higher in Cabot's Tragopans. The femoral stress of hatching Cabot's Tragopans was higher than hatching pigeons, but the stress of adult Cabot's Tragopans was lower than adult pigeons (Table 2).

\section{Strain energy density}

Under axial loading, the highest femoral SED of pigeons was observed in a 14-day-old individual, while it was observed in the 14- and 21-day-old individuals under radial loading (Fig. 3). The other pigeons had similar SED values among each other. In Cabot's Tragopans, the femoral SED showed a general stable trend with growth; the SED of $\mathrm{H} 1$ was lower than the average SED of adults under both loading conditions. The femoral SED of Cabot's Tragopans was lower than pigeons in all the growth stages, and young birds of the two showed the greatest divergence (Table 2).

Table 1 Relationships used in the assignation of material property in modeling

\begin{tabular}{|c|c|c|c|}
\hline Species & Age or stage $\mathrm{a}^{\mathrm{a}}$ & $H U-\rho$ & $\rho-E$ \\
\hline \multirow[t]{2}{*}{ Pigeon } & 4 to 14 days & $\rho=5.47 \times 10^{-4} \mathrm{HU}+0.31$ & $E=995.20 \times \rho^{4.74}$ \\
\hline & Other & $\rho=3.20 \times 10^{-4} \mathrm{HU}+0.15$ & \\
\hline \multirow[t]{2}{*}{ Cabot's Tragopan } & $\mathrm{H} 1$ & $\rho=2.67 \times 10^{-4} \mathrm{HU}+0.12$ & $E=2588.65 \times \rho^{4.32}$ \\
\hline & Other & $\rho=5.65 \times 10^{-4} \mathrm{HU}+0.33$ & \\
\hline
\end{tabular}

${ }^{a}$ Birds were grouped according to the size of the femora; each group has its specific scan settings 


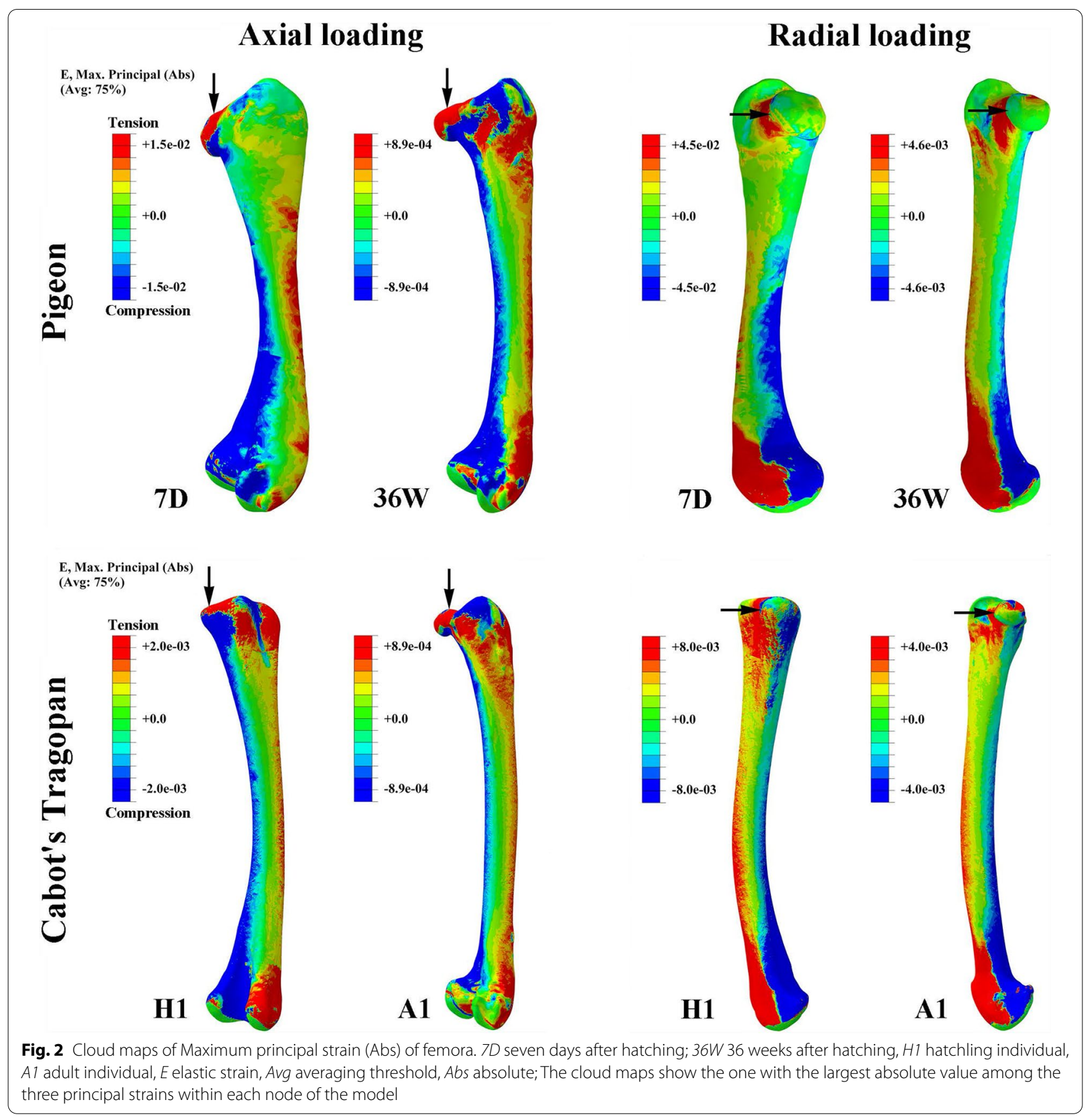

Interspecies comparison of precocity

The precocity of structural and material properties of hatching birds was calculated as the parametric ratio of hatchlings to adults. Pigeons exhibited a high structural precocity of femora, while Cabot's Tragopans exhibited a high precocity in the elastic modulus of femora (Table 3).

\section{Discussion}

Limb posture dominates femoral deformation

The femora of both the two birds showed dorso-ventral bending under radial loading and medio-lateral bending under axial loading; the bending orientation of the femora explicitly corresponded with the loading conditions. During terrestrial locomotion, the angle at which the 
a

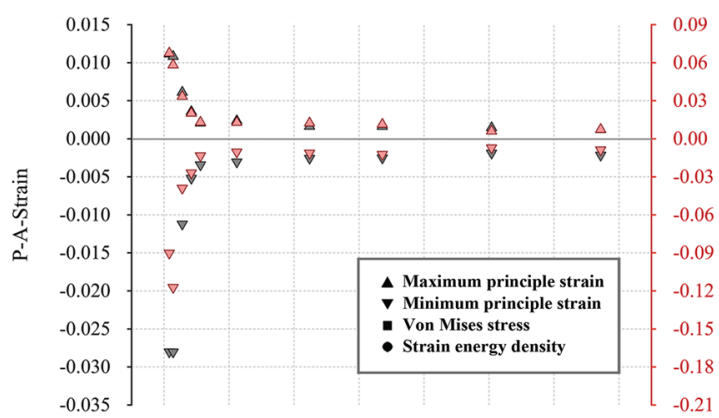

b

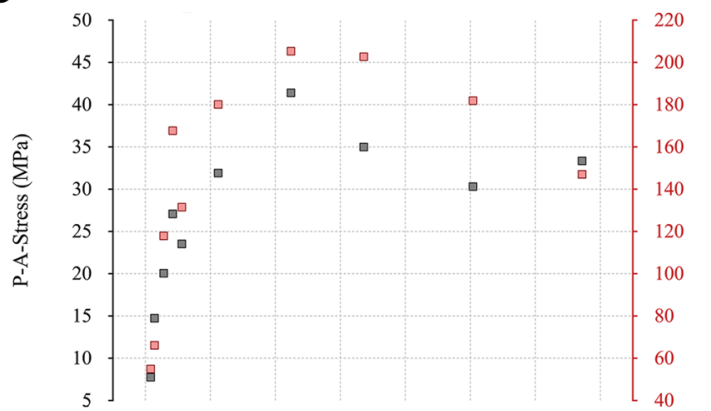

C

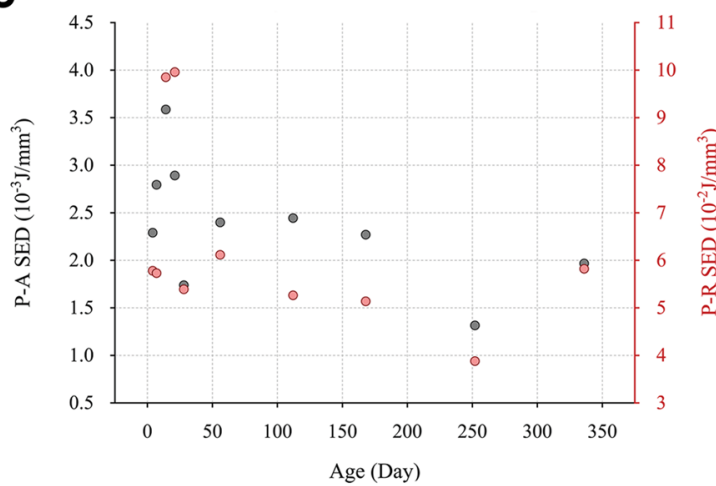

d

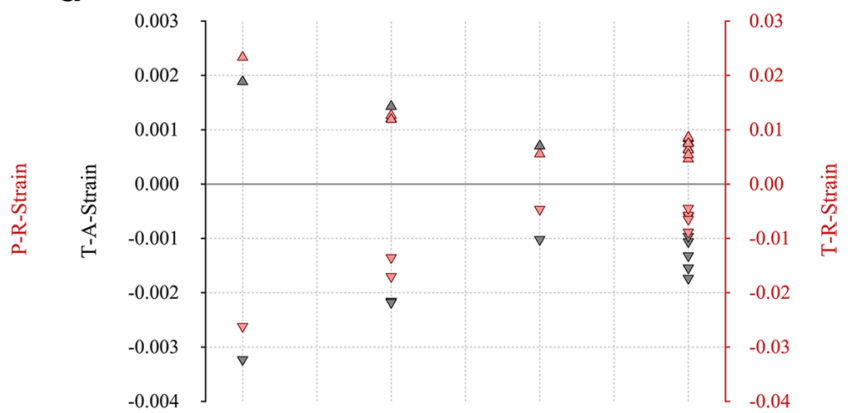

e

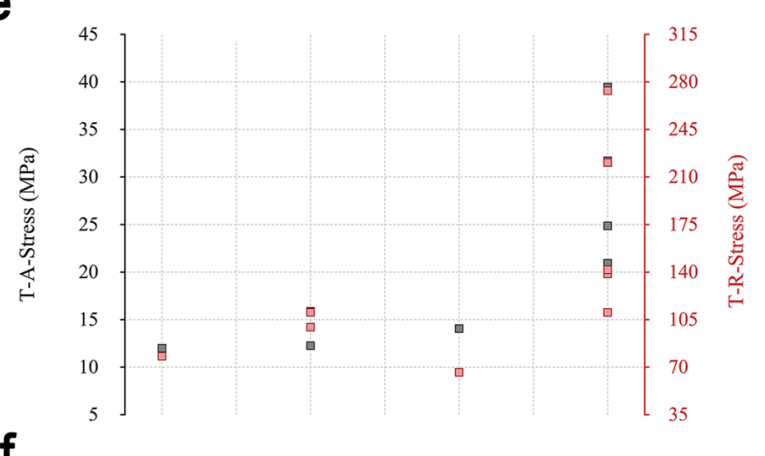

f

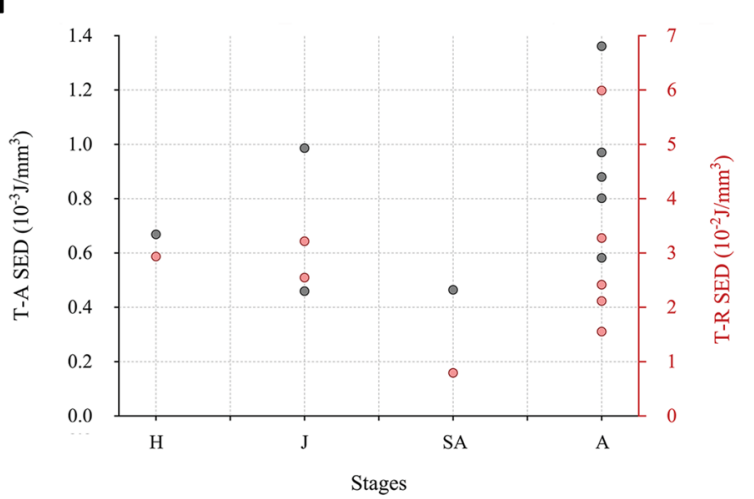

Fig. 3 Ontogenetic changes of the strain, stress, and SED of femora. P pigeon, T Cabot's Tragopan, $A$ axial loading, $R$ radial loading. Symbols filled in black and red indicate the results of axial and radial load analysis, respectively. Different parameters are distinguished by the shape of the symbols (As shown in the legend)

Table 2 Measurement ratio of Cabot's Tragopans to pigeons

\begin{tabular}{|c|c|c|c|c|c|c|c|c|}
\hline \multirow[t]{2}{*}{ Ratio } & \multicolumn{2}{|c|}{ Strain- $A$} & \multicolumn{2}{|c|}{ Strain- $R$} & \multicolumn{2}{|l|}{ SED } & \multicolumn{2}{|c|}{ Stress } \\
\hline & Min & Max & Min & $\operatorname{Max}$ & $A$ & $R$ & $A$ & $R$ \\
\hline T/P-hatchlings & 0.12 & 0.17 & 0.22 & 0.35 & 0.19 & 0.30 & 1.55 & 1.42 \\
\hline$T / P$-adults & 0.58 & 0.48 & 0.64 & 0.70 & 0.46 & 0.61 & 0.78 & 0.96 \\
\hline
\end{tabular}

T/P: ratio of Cabot's Tragopans to pigeons; Min: minimum principal strain; Max: maximum principal strain. $A$ : axial load; $R$ : radial load.

femur bears external force is related to the posture of the hind limb. A crouched posture of the hind limb tends to cause radial loading on the femur, while an erect posture tends to cause axial loading on the femur (Biewener 1989, 2005). Our results showed that femoral stress, strain, and SED due to radial loading was significantly larger than 
Table 3 The precocity of femoral structural and material properties of hatchlings

\begin{tabular}{|c|c|c|c|c|c|}
\hline Species & Elastic modulus & Bone length & Diameter & Cross sectional area & $\begin{array}{l}\text { Polar } \\
\text { moment of } \\
\text { inertia }\end{array}$ \\
\hline Pigeon & $0.72 \%$ & $47.25 \%$ & $58.11 \%$ & $59.41 \%$ & $19.48 \%$ \\
\hline Cabot's Tragopan & $11.62 \%$ & $26.14 \%$ & $28.33 \%$ & $6.21 \%$ & $0.51 \%$ \\
\hline
\end{tabular}

that of axial loading in all of the individuals, suggesting that the femur bears a high risk failure under radial loading. Furthermore, in the femora of both pigeons and Cabot's Tragopans, the compressive strain was larger than tensile strain under axial loading, whereas the two strain types were similar to each other under radial loading. As the acting orientation of axial loading parallels to the longitudinal axis of femora, the main proportion of the total load due to axial loading is born in compression rather than tension. Therefore, an erect posture of limbs will lead to a net decrease in the tensile deformation of femora, which makes good use of the outstanding compressive resistance of bones, and therefore achieves a high locomotor safety factor of femora (Currey 2002). Corresponding kinematic studies found that the hip joint movement of birds increases significantly with increasing speed during terrestrial locomotion (Cracraft 1971; Gatesy 1999; Abourachid et al. 2011; Stoessel and Fischer 2012). It makes the femora of birds more erect at the midstance of the stride. Because the mid-stance is generally the moment when the net ground reaction force reaches its maximum, the erect posture of the femur will enhance its resistance to loads during strenuous locomotion. Additionally, Biewener (2005) argued that the crouched posture will cause a reduction in the muscle's moment arm relative to the moment arm of the ground's reaction to the force of the limbs. This decreases the effective mechanical advantage of limbs. During locomotion, larger muscle force is needed in limbs with low effective mechanical advantage than that in limbs with high effective mechanical advantage.

Moreover, although the crouched posture of limbs leads to a low safety factor in bones, it enhances the maneuverability and accelerative capability of animals (Biewener 1989; Alexander 2003). Several studies suggested that terrestrial vertebrates with large body weight prefer an erect limb posture, while small animals prefer a crouched posture (Alexander et al. 1979a; Biewener 1982, 1989, 2005). The elastic modulus of long bones of vertebrates falls within a relatively narrow range (Erickson et al. 2002), and the breaking strengths of long bones are quite similar among mammals and birds across a huge range of body sizes (Biewener 1982). By adopting more erect postures, large animals decrease bone deformation and enhance the effective mechanical advantage of their limbs to overcome the locomotor limit of their large body weight. In contrast, small animals have a much smaller body mass relative to their bone strength than large animals (Biewener 1982). As such, the safety factor of bones may not be the primary consideration for them. However, small size also presents disadvantages for small animals. For example, small animals are more vulnerable to predators and experience a more diverse terrain (Hedenström and Rosén 2001; Herrel and Gibb 2006). Nevertheless, small animals have a high power-to-mass ratio, which makes them more maneuverable than large animals (Dial et al. 2008). Meanwhile, the crouched limb posture not only enhances their maneuverability but also their accelerative capability. These enhancements allow them to contend with large animals and escape from predators efficiently (Alexander 2003; Dial et al. 2008). This is probably the predominant reason that small animals prefer crouched postures.

\section{Species-specific mechanical performance}

The femoral strain and SED of young Cabot's Tragopans are lower than those of young pigeons, which suggest a higher femoral mechanical performance of young Cabot's Tragopans. Furthermore, the strain and SED of young and adult Cabot's Tragopans are similar, while these parameters sharply decline during growth in pigeons. This suggests that the femoral precocity of young Cabot's Tragopans is higher than that of young pigeons. The different femoral mechanical performance between the two birds corresponds well to the fact that precocial birds have higher locomotor demands than altricial birds. Furthermore, the femoral midshafts of 4- and 7-dayold pigeons have a relatively higher strain than that of older pigeons. The narrow midshaft in 4- and 7-day-old individuals may be responsible for their high femoral stress and strain. The narrow midshaft is very deformable and is, thus, not suitable for weight-bearing. However, pigeons cannot stand until they are 7 days of age, and, thus, the easily deformable shape is prevented from damaging the locomotion of young pigeons. Of note, the weak locomotor ability of young pigeons is also reflected in the structural characteristics of their femora.

This study has revealed that femoral stress increases with growth in both pigeons and Cabot's Tragopans. Stress is often adopted by studies to evaluate bone 
strength. As bones will fail at a certain stress level, the ratio of failure stress to load-induced stress is used as the safety factor of bones (Biewener 1982). However, the skeletal material property develops with animal growth and thereby failure stress increases as well (Currey 2002). We cannot clarify the ontogenetic change of the femoral safety factor based on the stress value alone. For the same reason, the finding that the femoral stress of Cabot's Tragopans is higher than that of pigeons does not imply that the femoral safety factor of pigeons is higher than that of Cabot's Tragopans. Stress is equal to the product of strain and elastic modulus. During the growth of the two birds, the femoral strain decreased while the stress increased. The femoral strain of 4-day-old pigeons under axial loading was $\sim$ tenfold that of adults, but the stress increased by $\sim 350 \%$ during growth. Therefore, the increase in stress with growth may be caused by the enhancement of the elastic modulus.

\section{The femora of precocial hatchlings are built to ensure locomotion ability}

Wei and Zhang (2019) observed the negative allometry of the breaking load of quail femora; the loading resistance of young quails was higher than that of adults. Similarly, the results of the present study showed that the femoral SED of young Cabot's Tragopans was lower than that of adults. The robust femora of young individuals are thought to be an adaptation to the intense locomotion required during their early growth stages (Wei and Zhang 2019). Due to weak parental care, precocial birds must forage and avoid predators independently or partially independently. Because of their small body size and immature sensory-motor system, young animals suffer the highest mortality rate and therefore the strongest selection pressure (Carrier 1996; Herrel and Gibb 2006). The locomotor ability of young animals is enhanced to cope with this strong selection pressure, which increases their survival rate. Therefore, the high mechanical performance of the femora of quails and Cabot's Tragopans is an adaptation to the high functional requirements of their bones that are needed to enhance the locomotion of young animals.

The femoral strain of young Cabot's Tragopans was lower than that of pigeons, which suggests that precocial birds have a high resistance to skeletal deformation. However, the strain of young Cabot's Tragopans was not lower than that of adults, unlike SED. This implies that young Cabot's Tragopans may have different preferences between deformation resistance and energy efficiency. The development of an organism is an energy-consuming event, and the available energy for young animals is limited (Ricklefs 1979a). Compared to altricial species, precocial species not only obtain little energy from parental birds but also consume more energy with their activity (Ricklefs 1979a). The rational distribution of energy is therefore critical for precocial animals. For this reason, the skeletal mechanical performance should not be enhanced without limit, as with this, energy may be wasted on unnecessary functions. Bones modulate their modeling and remodeling processes based on specific mechanical stimulus to optimize their mechanical performance (Carter 1984). Carter et al. (1987) argued that the apparent bone density is positively correlated to the apparent SED. Combining this conclusion with our results, we hypothesize that SED is the bone modeling/ remodeling stimulus. SED is affected by both stress and strain. A high SED value implies high stress and/or strain, which harms the performance of bones. Nevertheless, an extremely low SED value may reflect excessive bone volume, and therefore more weight and consequentially higher energy consumption. Skeletal SED may be maintained within a reasonable range to meet the mechanical performance requirements of strength, rigidity, and lightweight together with limited energy sources.

The femora of Cabot's Tragopans showed decreased strain with growth. In contrast, two studies employing in vivo strain tests have observed another ontogenetic trajectories in the bone strain of birds. The strain of the tibiotarsus remained constant during chick growth (Biewener et al. 1986), while the strain of the femur and tibiotarsus increased with emu growth (Main and Biewener 2007). Although the ground-dwelling birds were used as the research objects in these two studies as well, they adopted the in vivo strain test which is different from our study. The results of in vivo strain tests reflect the effects of locomotion on bones, while the results of the present study reflect the mechanical performance of bones. Therefore, the different strain results between the present study and the two abovementioned in vivo studies are not contradictory. Furthermore, if the in vivo femoral strain of Cabot's Tragopans maintains or decreases with growth, which is just like that of the chick and emu assessed in Biewener et al. (1986) and Main and Biewener (2007), respectively, young Cabot's Tragopans must have some mechanisms that decrease bone strain, because our results showed that the femoral strain decreased with growth under body weight loading alone. Biewener and Taylor (1986) suggested that an animal's gait and speed during locomotion is limited by the magnitude of bone strain. Therefore, if young Cabot's Tragopans indeed have some strain-reducing mechanisms, they can achieve a relatively higher speed than adults under the same conditions of bone mechanical performance. The strain-reducing mechanisms decrease the functional demands on the mechanical performance of bones, which improves the locomotor ability of young Cabot's Tragopans. 


\section{The robust femoral structure of altricial hatchlings adapts to rapid growth}

Pigeons hatch with weak femora, which corresponds to their low demands for locomotion. However, the femoral structure of hatchling pigeons is relatively more robust than that of hatchling Cabot's Tragopans. This implies that the weak mechanical performance of femora is not simply the result of a correlation between low performance and low functional demands. Carrier and Leon (1990) found that in California Gulls, the growth of wing bone length begins immediately after hatching, whereas other wing tissues do not develop until shortly before fledging. Carrier and Leon (1990) suggested that the linear growth of bones may require more time than other tissues, and that therefore the linear growth of long bones could be the rate-limiting factor in limb development. After that, Carrier and Auriemma (1992) found that the fledging period of birds has a strong positive correlation with relative bone length. This result supports the hypothesis of Carrier and Leon (1990). Cosman et al. (2019) then revealed the reason for this phenomenon, that is, rapid linear growth of bone leads to changes in the organic bony matrix composition of the bone, which makes the bone brittle and susceptive to fracture by even the smallest deformation. Thus, bone growth must be initiated earlier so as to prevent longer maturation durations. Therefore, the high structural precocity of pigeon femora may be an adaptive trait to rapid growth.

As altricial birds, pigeons exhibited rapid growth rates regarding femoral mechanical performance. Their femora were extremely deformable at hatching; however, the bone strain reached adult levels at 28 days after hatching, which exactly coincides with the fledging time. In contrast, the femoral strain of Cabot's Tragopans reached adult levels at the sub-adult stage (individual SA1). According to the growth curve of Cabot's Tragopans in Wen and Zheng (1998), it can be estimated that the age of the Cabot's Tragopan SA1 was 70-80 days. The long developmental period of Cabot's Tragopans provides sufficient time for bones to grow slowly, while pigeons need robust bone structures at hatching that enable maturation in just 4 weeks.

California Gulls show constant bone growth already from hatching onwards (Carrier and Leon 1990), while pigeons not only exhibit constant bone growth but also a robust bone structure at hatching. Additionally, the development of the cross-sectional bone structure was delayed in California Gulls but not in pigeons. This difference may be caused by the different demands on the rapid growth between the two birds. Altricial pigeons have more rapid growth than semi-precocial California Gulls; pigeons may, thus, have better developed bone structures at the time of hatching to support their rapid growth in comparison to gulls. This may imply that more altricial birds exhibit more robust bone structures. If a negative relationship between the precocity of hatchling birds and the precocity of long bone structures is proven, the type of hatchling birds can be inferred based on the bone structure. These results have potential applications for studies regarding developmental patterns of fossil avian species.

The methods used in the present study have some limitations as in other previous similar works. First, the elastic modulus is calculated from the three-point bending test using equations from beam theory. Because the shape and geometry of the femur are complex and irregular, beam theory only provides rough estimation of material properties (Jepsen et al. 2015). Second, the mechanical test requires the sample to be machined to standard size and tested in a particular loading mode, but this standard protocol cannot be applied to birds' femur because of the small size. Fortunately, it has been proved that the beam theory combined with the mechanical test has high precision in estimating elastic modulus of bones (Arias-Moreno et al. 2020), which enhances the credibility of the present research. In particular, these methods are more suitable for comparative and ontogenetic analysis on the biomechanical performance of animals' limb bone.

\section{Conclusions}

The deformation of the femur is greatly affected by the load angle and is thus dominated by the posture of the limb. A more erect hind limb will cause less deformation to the femur, which supports the conclusion that the erect posture of large animals would enhance the safety factor of their long bones (Biewener 1982, 1989). During postnatal ontogeny, the femora of Cabot's Tragopans and pigeons undergo very different growth patterns in their mechanical performance. Cabot's Tragopans hatch with well-developed and strong femora, which enable hatchling pheasants for high locomotion demands. The femur of hatchling pigeons is too weak to support the body, but the femoral structure is particularly robust and is considered to be an adaptation to rapid growth. The femora of adult Cabot's Tragopans are stronger than that of pigeons, corresponding to a more terrestrial habit. The results of the present study reflect the close correlation between the mechanical performance of bones and animal locomotion, and provide a basis for inferring the behaviors of extinct animals based on bone remains in fossil studies.

\footnotetext{
Acknowledgements

We thank Yanyun Zhang from the College of Life Sciences, Beijing Normal University, for providing bird samples, and our lab members for assistance in sample processing. We are grateful to Qunbo Fan from the School of Materials
} 
Science \& Engineering, Beijing Institute of Technology, Baoqing Pei from the School of Biological Science and Medical Engineering, Beihang University, Yangwei Wang and Tao Sun for technical support; Maja Mielke and an anonymous reviewer for constructive comments that improved the study; enago for language editing service.

\section{Authors' contributions}

XW and ZZ conceived and designed this study. XW performed the experiments and data analysis. XW and ZZ wrote the manuscript. All authors read and approved the final manuscript.

\section{Funding}

This work was supported by the National Natural Science Foundation of China (No. 31471951).

\section{Availability of data and materials}

The datasets used and/or analysed during the current study are available from the corresponding author on reasonable request.

\section{Declarations}

\section{Ethics approval and consent to participate}

The project was approved by the Animal Care and Ethics Committee of Capital Normal University.

\section{Consent for publication}

Not applicable.

\section{Competing interests}

The authors declare that they have no competing interests.

Received: 5 January 2021 Accepted: 18 April 2021

Published online: 24 April 2021

\section{References}

Abourachid A, Hackert R, Herbin M, Libourel PA, Lambert F, Gioanni H, et al. Bird terrestrial locomotion as revealed by 3D kinematics. Zoology. 2011;114:360-8.

Alexander RM. Principles of animal locomotion. Princeton: Princeton University Press; 2003

Alexander RM, Jayes AS, Maloiy GMO, Wathuta EM. Allometry of the limb bones of mammals from shrews (Sorex) to elephant (Loxodonta). J Zool. 1979a;189:305-14.

Alexander RM, Maloiy GMO, Njau R, Jayes AS. Mechanics of running of the ostrich (Struthio camelus). J Zool. 1979b;187:169-78.

Alexander RM, Ker RF, Bennett MB. Optimum stiffness for leg bones. J Zool. 1990;222:471-8

Arias-Moreno AJ, Ito K, van Rietbergen B. Accuracy of beam theory for estimating bone tissue modulus and yield stress from 3-point bending tests on rat femora. J Biomech. 2020;101:109654.

Biewener AA. Bone strength in small mammals and bipedal birds: do safety factors change with body size? J Exp Biol. 1982;98:289-301.

Biewener AA. Scaling body support in mammals: limb posture and muscle mechanics. Science. 1989;245:45-8.

Biewener AA. Biomechanical consequences of scaling. J Exp Biol. 2005;208:1665-76.

Biewener AA, Taylor CR. Bone strain: a determinant of gait and speed? J Exp Biol. 1986;123:383-400.

Biewener AA, Swartz SM, Bertram JE. Bone modeling during growth: dynamic strain equilibrium in the chick tibiotarsus. Calcif Tissue Int. 1986;39:390-5.

Bishop PJ, Hocknull SA, Clemente CJ, Hutchinson JR, Barrett RS, Lloyd DG. Cancellous bone and theropod dinosaur locomotion Part II-a new approach to inferring posture and locomotor biomechanics in extinct tetrapod vertebrates. PeerJ. 2018;6:e5779.

Carrier DR. Ontogenetic limits on locomotor performance. Physiol Zool. 1996;69:467-88.

Carrier DR, Auriemma J. A developmental constraint on the fledging time of birds. Biol J Linn Soc. 1992;47:61-77.
Carrier DR, Leon LR. Skeletal growth and function in the California gull (Larus californicus). J Zool. 1990;222:375-89.

Carter DR. Mechanical loading histories and cortical bone remodeling. Calcif Tissue Int. 1984;36(Suppl 1):S19-24.

Carter DR, Fyhrie DP, Whalen RT. Trabecular bone density and loading history: regulation of connective tissue biology by mechanical energy. J Biomech. 1987;20:785-94.

Clark J, Alexander RM. Mechanics of running by quail (Coturnix). J Zool. 1975;176:87-113.

Cosman MN, Britz HM, Rolian C. Selection for longer limbs in mice increases bone stiffness and brittleness, but does not alter bending strength. J Exp Biol. 2019. https://doi.org/10.1242/jeb.203125.

Cracraft JL. The functional morphology of the hind limb of the domestic pigeon, Columba livia. Bull Am Mus Nat Hist. 1971;144:171-268.

Crawford RP, Cann CE, Keaveny TM. Finite element models predict in vitro vertebral body compressive strength better than quantitative computed tomography. Bone. 2003;33:744-50.

Currey JD. What determines the bending strength of compact bone? J Exp Biol. 1999;202:2495-503.

Currey JD. Bones: structure and mechanics. Princeton: Princeton University Press; 2002

Currey JD. How well are bones designed to resist fracture. J Bone Miner Res. 2003;18:591-8.

Dial KP, Greene E, Irschick DJ. Allometry of behavior. Trends Ecol Evol. 2008;23:394-401.

Doblaré M, García JM, Gómez MJ. Modelling bone tissue fracture and healing: a review. Eng Fract Mech. 2004;71:1809-40.

Doube M, Kłosowski MM, Arganda-Carreras I, Cordelières FP, Dougherty RP, Jackson JS, et al. BoneJ: free and extensible bone image analysis in ImageJ. Bone. 2010;47:1076-9.

Dumont ER, Grosse IR, Slater GJ. Requirements for comparing the performance of finite element models of biological structures. J Theor Biol. 2009;256:96-103.

Eberle S, Göttlinger M, Augat P. Individual density-elasticity relationships improve accuracy of subject-specific finite element models of human femurs. J Biomech. 2013:46:2152-7.

Erickson GM, Catanese J III, Keaveny TM. Evolution of the biomechanical material properties of the femur. Anat Rec. 2002;268:115-24.

Gatesy SM. Guineafowl hind limb function. I: cineradiographic analysis and speed effects. J Morphol. 1999;240:115-25.

Gere JM. Mechanics of materials. Pacific Grove: Brooks/Cole Thomson Learning; 2001.

Goetz JE, Derrick TR, Pedersen DR, Robinson DA, Conzemius MG, Baer TE, et al. Hip joint contact force in the emu (Dromaius novaehollandiae) during normal level walking. J Biomech. 2008;41:770-8.

Hedenström A, Rosén M. Predator versus prey: on aerial hunting and escape strategies in birds. Behav Ecol. 2001;12:150-6.

Helgason B, Perilli E, Schileo E, Taddei F, Brynjólfsson S, Viceconti M. Mathematical relationships between bone density and mechanical properties: a literature review. Clin Biomech. 2008;23:135-46.

Herrel A, Gibb AC. Ontogeny of performance in vertebrates. Physiol Biochem Zool. 2006;79:1-6.

Jepsen KJ, Silva MJ, Vashishth D, Guo XE, van der Meulen MC. Establishing biomechanical mechanisms in mouse models: practical guidelines for systematically evaluating phenotypic changes in the diaphyses of long bones. J Bone Miner Res. 2015;30:951-66.

Main RP, Biewener AA. Skeletal strain patterns and growth in the emu hindlimb during ontogeny. J Exp Biol. 2007;210:2676-90.

Morgan EF, Bouxsein ML. Use of finite element analysis to assess bone strength. BoneKEy-Osteovision. 2005;2:8-19.

Olea G, Hernando A, Lombardo D. Heterochronic events in the ontogeny of Columba livia, Coturnix coturnix and Gallus gallus domesticus. Rev Colomb Cienc Pecu. 2016;29:274-82.

Pelker RR, Friedlaender GE, Markham TC, Panjabi MM, Moen CJ. Effects of freezing and freeze-drying on the biomechanical properties of rat bone. J Orthop Res. 1984;1:405-11.

Rayfield EJ. Finite element analysis and understanding the biomechanics and evolution of living and fossil organisms. Annu Rev Earth Planet Sci. 2007;35:541-76. 
Rayfield EJ. What does musculoskeletal mechanics tell us about evolution of form and function in vertebrates? In: Bels V, Whishaw I, editors. Feeding in vertebrates. Berlin: Springer; 2019. p. 45-70.

Ricklefs RE. Adaptation, constraint, and compromise in avian postnatal development. Biol Rev Camb Philos Soc. 1979a;54:269-90.

Ricklefs RE. Patterns of growth in birds. V. A comparative study of development in the starling, common tern, and Japanese quail. Auk. 1979b;96:10-30.

Ruff CB, Holt B, Trinkaus E. Who's afraid of the big bad Wolff?: "Wolff's law" and bone functional adaptation. Am J Phys Anthropol. 2006;129:484-98.

Stoessel A, Fischer MS. Comparative intralimb coordination in avian bipedal locomotion. J Exp Biol. 2012;215:4055-69.
Wang L, Wei XS, Liang XX, Zhang ZH. Ontogenetic changes of hindlimb muscle mass in Cabot's tragopan (Galliformes, Phasianidae) and their functional implications. Anat Rec. 2021. https://doi.org/10.1002/ar.24609.

Wei X, Zhang Z. Ontogenetic changes of geometrical and mechanical characteristics of the avian femur: a comparison between precocial and altricial birds. J Anat. 2019;235:903-11.

Wen Z, Zheng G. Artificial raising and breeding of Cabot's Tragopan (Tragopan caboti). Chin J Zool. 1998;33:22-7 (in Chinese)
Ready to submit your research? Choose BMC and benefit from:

- fast, convenient online submission

- thorough peer review by experienced researchers in your field

- rapid publication on acceptance

- support for research data, including large and complex data types

- gold Open Access which fosters wider collaboration and increased citations

- maximum visibility for your research: over $100 \mathrm{M}$ website views per year

At BMC, research is always in progress.

Learn more biomedcentral.com/submissions 